\title{
DEVELOPMENT OF ERP AND OTHER LARGE BUSINESS SYSTEMS IN THE CONTEXT OF NEW TRENDS AND TECHNOLOGIES
}

\author{
Sabrina Suman \& Ivan Pogarcic
}
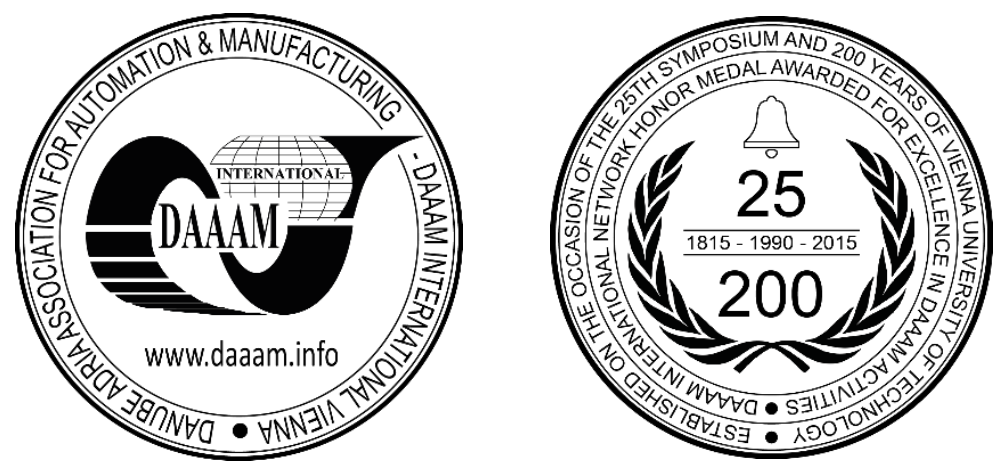

This Publication has to be referred as: Suman, S[abrina] \& Pogarcic, I[van] (2016). Development of ERP and Other Large Business Systems in the Context of New Trends and Technologies, Proceedings of the 27th DAAAM International Symposium, pp.0319-0327, B. Katalinic (Ed.), Published by DAAAM International, ISBN 978-3-90273408-2, ISSN 1726-9679, Vienna, Austria

DOI: $10.2507 / 27$ th.daaam.proceedings.047

\begin{abstract}
This paper presents an overview of terms, concepts, trends and technologies that are relevant to today's business. It describes the basics of data and information integration and flow in a company through a central ERP system with concepts of CRM and SCM. The emergence of big data as a tributary of a huge number of often unstructured data from different sources can become a central problem or opportunity for advancement and achievement of competitive advantages of a company. Ignorance of key figures and/or the non-acceptance of new business conditions, new technologies and possible deployment solutions are the main reasons for non-productivity and poor business performance. To demonstrate the dynamics of appearance and popularity of terms, concepts, trends and technologies this paper offers a tabular overview of the frequencies based on the data from 3 global databases. Meta analysis shows the expected future development of analytical trends and technologies. This paper is intended for those who lead, run and participate in projects of implementation of large software systems, dealing with quality management of business, or want to understand the complexity of this area and the future directions of development.
\end{abstract}

Keywords: ERP; BI; DSS; SCM; CRM; big data.

\section{Introduction}

Getting specific information for specific job-situation-task, means that data from different sources must continuously be collected, stored and analyzed. Care and use of so much data is impossible without a well-structured database and/or data warehouse, and the analysis of this data is impossible without a series of BI (Business Intelligence) tools. Information therefore needs to be within easy reach and analyzed in order to give effect to the business objectives [1], and information systems should be changed, integrated and introduced precisely in order to realize this goal. [2]

Companies whose executives understand data as a core asset and resources of business are six times more likely to be successful than those whose top management does not perceive data in this way (31\% vs. 5\%) and have a lot more success with BI projects. [3].

Technological progress and the information needs of companies today create a continuous cycle of growing needs for ever more effective ways of coverage and analysis of data in and around the company. Currently, the society is faced with a growing, large and various sources of data, which is often referred to as big data, and is used for decision 
support. Big data are complex, layered, large amounts of data and finding i.e. getting the right information in such a large amount of data is like searching for a needle in a haystack, and the greater the amount of data it is more difficult to find the true value of the data. [4].

Many observers, including [5], [6], [7] and [8] argue that the potential of using big data to improve the personal life or to help companies to compete is unlimited. According to [6], "better access to information and technology for the management and analysis of data is changing the world." In a way, big data will lead to better health, better teachers, improved education, and better decision-making. Gartner hype curve predicts that the big data for two to five years [9] will do much to transform and influence the business.

The goal is not the production and use of vast amounts of data, but the way the data is being analyzed and presented, which techniques are being used to get valuable information and the right support and a base for decision making, and in reality it is about big analytics not just about big data [10] [11]. [12] argues that the management and analysis of these data is precisely the most difficult part in the field of big data. Availability and timeliness of the results of quality analysis in the moments when you have to make decisions is a major challenge. Such phenomena of large amounts of data, and the need for high-quality analysis also require new expertise and experts in many organizations [13].

After describing the perceived problems caused by the appearance of massive amounts of data from various sources, we can see the importance of choosing and using various software tools, technologies and techniques and the efficient management of all data concerning the business seems like a prerequisite for the survival of the various activities of the company.

In consideration of the successful management of a company interaction of large-scale integrated enterprise systems such as ERP, CRM, and SCM with the DSS and BIS is also important, where analytics of business intelligence based on integrated data of the entire company can directly affect a more quality, timely and flexible decision support, and decisions will again directly affect the effectiveness of CRM and SCM. [14].

Setting an ERP for the origin of this systematic review is also reflected in the main target for the implementation of an ERP - access to data in a controlled manner at the level of the entire company and information sharing across business processes [15]. [16] suggest that a suitable choice of an ERP system provides results such as increased productivity, punctual delivery, decreased implementation time, and reduced price of a product while a bad choice of an ERP system leads to project failure or performance degradation of a company.

Furthermore, a review links together concepts of BI, DSS - Decision Support Systems, SCM - Supply Chain Management, CRM - Customer Relationship Management, BPM - Business Performance Management with the involvement of the big data sphere. Also shown is the dynamic of representation of concepts from the paper through publications of 3 global scientific-technical databases from 1991-2016 in phases of 5 years. To view the future development of new trends and technologies related to retrieving, storing and analyzing information, generated was a graphical representation obtained by meta analysis of research [17].

Objective of the paper is to review and synthesize the inter-related areas that need to be considered in today's business.

Purpose of the work is to indicate the complexity of the successful implementation of maintenance and future development of ERP and other business systems through a systematic review of interrelationships of large systems, new technologies and trends.

\section{Overview of connection between the ERP and business-critical systems}

This section will connect the following terms and concepts: ERP (Enterprise Resource Planning), DSS (Decision support system), BI (Business Intelligence), CRM (Customer Relationship Managemenet), SCM-(Supply Chain Managemenet), BPM (Business performance Management), DW (Data Warehouse, Data Warehousing), KM (Knowledge management) and MEC (Multi Enterprise Collaboration). The objectives of this chapter are:

- To stress the importance, function, purpose and potential benefits of ERP systems,

- To point out the known problems and bad practices observed in the planning and/or after the implementation of ERP in the company,

- To include the actuality of today's business conditions, which requires inter-organizational collaboration - MEC (Multi-Enterprise Collaboration) in decision-making and technological implications and possible solutions to such business.

- To show links of the ERP systems with other large systems, the importance of connection between these systems and the consequent implications of these connections on the criteria in the selection of software modules and ways of implementation

- List some guidance on the selection of software packages related to big business systems and the type of BI analytics

\section{1. $E R P$}

ERP software automates and integrates business processes and enables the sharing of information and data in a variety of business functions. ERP software enhances the functionality and efficiency of business processes that take place in the departments of finance, human resources, operations and logistics, and sales and markets [18]. Since it 
affects the entire business, or at least a large part of the business, and its purchase and introduction is a large organizational cost, selection of an ERP system is a particularly complex and delicate task. It is estimated that 40-70\% of ERP implementations have experienced some type of failure [19]. Determination of the potential benefits of ERP implementation is a challenging task, because most of the advantages do not come from the ERP system, but from different ways in which the system can be implemented and used. Although this is true for any type of information system (IS), it is a special burning question for the ERP systems, because of their decisive influence on almost all aspects of the organization. This is even more important in the context of ERP implementation through multiorganization, a subject of work by Eckartz et al. [20].

Companies that decide to introduce the ERP systems are often inspired by imitation of successful practices in similar companies. Such a conviction management board can lead to so-called homogenization of companies which weakens the differentiation, i.e. the uniqueness or specificity by which a company and its products are recognized and stand out in the market. The loss of differentiation and uniqueness can weaken the company's potential and performance that delivers business value. [21] emphasizes the importance of detailed and elaborate evaluation protocols and practices to choose the solution that best suits the company instead of imitating the competitors. This argues the need to inform about all the influential factors of the optimal selection of ERP solutions and overall quality management of performance and operations of the company.

Complexity of approach in the selection of an ERP and the number of factors that affect the success of the implementation was discussed gradually in the further part of the review where the function, purpose, benefits and success of ERP are viewed in relation to the relevant terms of the wider area of managing the performance of a company.

\subsection{ERP and decision making support}

Davenport [22] suggests that the main reason and the greatest potential of ERP is making quality and timely decisions, and Palaniswamy and Frank [23] concluded that the ERP is a prerequisite for decision making support. Part of the research on the effects of ERP to support the decision making proved that ERP systems offer significant benefits in the area of decision making support [24].

Although ERP systems integrate knowledge and provide reporting tools for users to analyze data, decision making support is not their primary purpose. This is supported by a multitude of BI software solutions which the company uses to implement a decision support system, which can not be fully developed only with an ERP solution. Therefore, it can be said that the quality of implementation of ERP systems is closely linked to the quality of the decision making system [25].

\subsection{ERP and Business Intelligence}

Business intelligence is a huge opportunity for any company to collect valuable insights from all the data covered by their ERP and those of other systems. Li [26], referring to the need for the ERP systems to link internal and external data, identifies the need to create an effective business intelligence as the primary objective of an ERP system.

BI software enables companies' quality and quick decision-making because of the availability of data and information in an easily customizable form. The standard functionality of the BI software allows DSS to use the data from the data warehouse, shaped to measure. This warehouse provides management with BI analytical tools, the ability to create ad hoc reports, graphics, tables, use graphical dashboards that offer information through financial statements, scorecards and KPIs (key performance indicators).

BI software is also available as a stand-alone package and as modules in ERP solutions. In recent years, ERP vendors have included BI products and sell them in their systems and have thus made way for potentially highly effective solutions that put on the business-user the new burdens of selection, costs of consultants, education etc. In addition to the BI module, many ERP vendors include the very ERP functionality of managing client interactions and promotional campaigns, but such applications are sold as separate software, such as SAP CRM and Oracle's Siebel CRM applications that have additional management capabilities with client activities.

\subsection{ERP and multi-organizational collaboration}

Tools for decision making support and application should be open and flexible enough, not only to provide support within their own organization, but also across organizational boundaries. It stresses the need for research of multiorganizational decision-making and the development of IT which will support and optimize the production [27] and in other areas of business. These includes heterogeneity in terms of the breadth and depth of data, complexity in terms of models, algorithms for solution and data visualization / process, distribution to the scope and range, versatility of domains and paradigms, flexibility, ability to reuse and extensibility [28].

More recently, vendors, including Microsoft, SAP and Oracle have introduced tools and systems that support decision-making aspect of the MEC (MEC, multi-enterprise collaborative). The shift of the market and scientific research towards this field of research is still in its early stages and new perspectives and insights are constantly being acquired as new products are being released. 


\subsection{ERP, data warehouse and knowledge management}

[29] point out that the knowledge of the employee is the most important resource of the company, and point out that although the repositories of knowledge in companies often exist, they are not organized in a way that they could be effectively used. The authors [30] observed the importance of integrating the processes of knowledge management (KM) within the Decision Support System so that the decision-makers can combine different types of knowledge (explicit and implicit) and data (internal and external) available in various forms. Improved creation and sharing of knowledge should increase the flexibility and innovation [31]. Literature dealing with ERP success suggests careful knowledge management in order to maximize its potential. Results of the Ifinedo research (Ifinedo, 2006) [32] have shown that knowledge management, including the creation of knowledge, is a strong predictor of ERP success. The more implicit and explicit knowledge the organization has, the more likely that the ERP will be successful [33].

Knowledge exists in the heads of corporate staff and management. Knowledge also exists in the environment outside of the company. The needs of business are also to formalize, store, access and use the entire knowledge of the company.

Data warehousing is not just a problem-solving process, but also a concrete architecture. Different companies have different data warehouses. According to the features of their ERP systems, many companies have designed the architecture of their data warehouses. Data warehouse is responsible for providing the information needed to support decision-making at different levels [34].

Existing data warehouse of a company can be extended to create a knowledge warehouse (KW) [35]. KW will not only facilitate the retrieval and creation of knowledge, but will also improve the retrieval and exchange of knowledge through the organization, providing at the decision-maker's disposal an intelligent platform for analysis. Knowledge warehouses will be continuously upgraded, with the aim of structuring knowledge from previous situations of decisionmaking and optimize future decisions. Shafiei et al., also mention the concept of a knowledge warehouse (KW) which is "above" the analysis of data from the ERP system via a data warehouse. [28]. [36] is also in the same vein, that with the advancement of technology expects that the existing business system will provide current intelligence information and not just the numbers, which can be used for making business decisions and strategies. This trend and the need are applicable today through various methods of artificial intelligence, especially in areas of text processing and natural language.

\subsection{ERP and CRM}

With the goal of providing "a single face to the customer," the basic principle behind CRM is that every employee in contact with the client must have access to information on the latest customer interactions with the company [37]. While CRM tools within an ERP, such as the SAP ERP system, when used properly, can help in the management of customer relationships, companies that opt for the concept of CRM often use a separate CRM system that communicates with the ERP system. The advantage of this approach is that the planning and analysis conducted in the CRM system does not interfere with the performance of the ERP system, which primarily handles large volumes of business transactions.

When compared with ERP, for CRM can be said that it, just like the ERP, offers ways to automate the process and conduct business more efficiently. However, these two systems are designed to streamline the various functions. While CRM is used to manage contacts, accounts, opportunities, activities, marketing, etc., ERP is designed to manage the operations and business functions, such as product planning, purchasing, inventory, customer service, order tracking and other back-end business processes. However, after the ERP vendors included the CRM features in their software, and CRM vendors included ERP capabilities into their tenders, the differences between them began to disappear.

\subsection{ERP and SCM}

The study [38] has empirically proven theoretical assumptions in the existing literature on the impact of ERP benefits on SCM competencies. A typical configuration of business software in the manufacturing enterprise includes at least three large systems ERP, SCM and CRM. All are constructed of one or more database management systems (DBMS) - which usually use the same logical integrated database. ERP, SCM and CRM systems are usually standard software that can adapt to the requirements of individual organizations. Today, these three types of systems tend to be integrated: SCM module, for example, will have access to information available in the ERP system directly or through a common database [39].

Supply Chain Management (SCM) is directed across boundaries, taking into account that companies are increasingly concentrating on their core competencies, leaving the other activities to the partners who have more knowledge. With the growing dependence on partners, effective supply chain has become equally important to the success of the company as the efficiency of internal business processes. Information systems that support supply chain management (SCM systems) are developed either by ERP vendors or software companies specializing in logistics. They have either expanded their ERP systems with additional SCM functions or developed new SCM systems that collaborate with their ERP systems.

Software companies are developing dedicated SCM systems and providing interfaces to standard ERP systems. The reason for this is that the SCM without ERP is hardly possible. An interesting trend is that some specialized SCM 
vendors were bought by large ERP vendors. In this way, ERP vendors are now able to offer supply chain management as part of their business portfolio. A typical company today uses a large number of information systems. These systems tend to be integrated, so that they can work together [39].

\subsection{ERP and BPM}

Over time, it turned out that, despite the fact that ERP systems hold most of the organization's data, they can provide insight into valuable information necessary for strategic decision making. ERP vendors are aware of this and offer BI functionality with their software to help "liberate" the data from these complex systems. At its core, BI is designed to consolidate data that extends across different business areas and systems, and help managers to make better decisions faster. In the new paradigm, the ERP system acts as an important source of data, but not necessarily the only source. This opens the door to choice to combine ERP with BI and/or Performance Management Suites and tools that meet the needs of the organization. This may or may not be from the same vendor.

In order to differentiate concise terms BI and BPM it is stated that BI discloses a technology used to access, analyze and inform about relevant business information. It covers a wide range of software solutions, including ad hoc queries, OLAP, dashboards, scorecards, today usually as modules for various BI suite. BPM is characterized as BI + strategic planning, which means that the convergence of BPM and BI planning is on a unified platform, cycle of planmonitoring-analysis. Processes that include BPM are not new: they exist in every medium to a larger organization, and BPM provides a framework for the integration of processes, methodologies and metrics of other systems into a single solution. Term BPM refers to the processes, methodologies, metrics and technologies used by the company to scale, monitor and manage business performance. BPM is a continuous set of processes which, if properly carried out affects the entire organization from top to bottom. For BPM it is important to synchronize the entire company: it helps users to achieve goals that help the execution of the strategy and the adoption of value for all the stakeholders [40].

\section{Emergence of new technologies and trends - big data and embedded analytics}

The reasons for considering the development and potentials of ERP systems and the entire BPM system and big data are reflected in the new capabilities-functionalities of a broader business software system and exploiting new trends and technologies, as outlined below. A large amount of big data is unstructured, such as audio, video, text, and developed techniques of storage, processing and analysis of data types have evolved, there is a possibility that ERP is stored in and managed by a new system, the "knowledge hub" where the knowledge from inside and surrounding environment of the company will be stored and formalized integrally [41].

Taking into account the big data sphere allows analysis of data and transactions that are created outside the company. In this way, all stakeholders, customers, partners, suppliers are connected and the development of applications which will integrate data, models from different business perspectives is expected. Therefore, big data provides the ERP system with additional features and characteristics in relation to other systems, such as CRM and SCM, and thus adds value to the business.

Using data from big data sphere will also initiate some issues of privacy and data security and protection, and the movement of data will need to be constantly monitored and take into account the latest regulations. Also, the quality of the data in the ERP system can be disrupted after the integration of big data, so it is necessary to set some filters when downloading raw data.

These considerations relating to the question of the position of the ERP system and the expansion of the boundaries of the data relevant for the company, with the development of new technologies certainly point to new opportunities for additional functionality of ERP systems and consequently the entire BPM, whose potential can be achieved if new issues which may occur by using big data types are also considered. Problems and changes are mostly related to the processing, storage, analysis and quality of big data. Also, the integration of ERP systems and big data will require some changes in the activities of the stages in the life cycle of ERP systems as a change of requirements to be met by the ERP [41].

As the pace of business accelerates steadily, the company realizes that it is not enough just to analyze the data but the activities that are being imposed on the basis of the results of the data analysis must also be operationalized as soon as possible. This means that the aim is to exploit and share not only data, but also the results of the analysis, and exchange them through the business processes and applications, in order to shorten the time of decision making.

Operationalizing and embedding analytics consists of gaining insight on the necessary actions within the business processes that can be automated or provide support for decision-making. Analytics of different functionality and complexity are usually built into the dashboards, applications, devices, systems, databases and the like. Operational 
analytics are in the background of logistics applications, some CRM modules, authorizations and detection of faults, the system recommended content and products for each customer and the like. Embedded analytics, while not entirely a new technology today is especially being taken into account due to the occurrence of big data, and the possibility of operationalization of decisions through programs is very effectively. Also, sharing analytics through a variety of applications allows them to be received and potentially exploited by a large number of stakeholders, which is certainly an added value [17].

\section{Research Methodology}

In order to show the development of individual concepts through four five-year periods chosen were two science databases (Web of Science, Core Collection, Science Direct), and the database Google Scholar, which shows a large number of scientific and professional publications regardless of the quality to compare dynamics of incidence and popularity. The last columns for each database show the Tendency, which results in a number 1 and the up arrow if constant growth was recorded, and otherwise 0 and arrow down. Attached you can find Table 3 obtained by meta analysis of research (for research details see under [17] which shows the current representation of the use of data types, analytical platforms and types of analytics and prediction for the next three years based on the responses of 300 respondents). The table was sorted by three categories from top to bottom by the intensity of shades: the first category represents concepts that are anticipated to decline in use over the next three years, and the remaining two categories indicate concepts that will be moderately more and much more used in the next designated period.

\section{Research results and discussion}

Table 1 is the representation of individual frequencies. In the first two databases the decline is shown only by the concept of Business Process Reengineering, while in the Google Scholar database more than one category shows a decline in participation in publications. Each topic was searched with quotation marks.

Table 2 shows the representation of publications that at the same time mention all the concepts related to the operator and a base WoS Core Collection is this time omitted due to the low number of publications for the first three five-year periods. Table 2 shows that in the Science Direct and Google Scholar databases the representation of the publications in which the selected concepts appear together is constantly growing to this day. This also shows the connection between ERP and other large systems with selected concepts, but in the last five years there has also been a noticeable expansion of considerations related to big data and embedded analytics.

\begin{tabular}{|c|c|c|c|c|c|c|c|c|c|c|c|c|c|c|c|c|c|c|}
\hline \multirow[b]{2}{*}{ Topic } & \multicolumn{6}{|c|}{$\begin{array}{c}\text { Web of Science Core Collection - Search } \\
\text { by Topic }\end{array}$} & \multicolumn{6}{|c|}{$\begin{array}{l}\text { Science Direct- Search by } \\
\text { Title,abstract,keywords }\end{array}$} & \multicolumn{6}{|c|}{$\begin{array}{c}\text { Google Scholar- Search all excluded citations } \\
\text { and patents }\end{array}$} \\
\hline & $\begin{array}{l}\frac{n}{2} \\
\frac{1}{2}\end{array}$ & 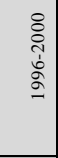 & 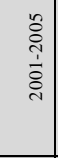 & 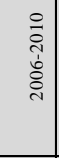 & 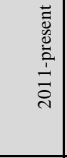 & 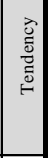 & $\frac{n}{\frac{2}{2}}$ & 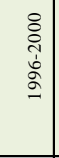 & 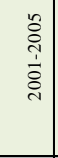 & 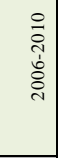 & 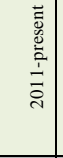 & 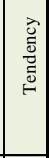 & $\frac{2}{\frac{1}{a}}$ & 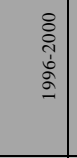 & 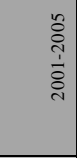 & 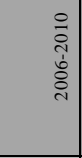 & 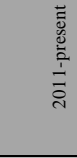 & 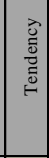 \\
\hline Decision Support & 1980 & 2857 & 3823 & 6505 & 11303 & 个 1 & 1022 & 1137 & 1456 & 2471 & 4545 & 수 1 & 18600 & 33200 & 92000 & 224000 & 154000 & $\sqrt{2} 0$ \\
\hline Enterprise Resource Planning & 2 & 54 & 264 & 350 & 380 & ث1 & 0 & 11 & 122 & 137 & 217 & 它 1 & 132 & 3160 & 14900 & 20400 & 17600 & $\sqrt{2} 0$ \\
\hline Business Performance Management & 0 & 0 & 2 & 6 & & ب 1 & 0 & 0 & 1 & 0 & & 个 1 & 30 & 109 & 860 & 2410 & 3590 & 个 1 \\
\hline Business Process Management & 6 & 31 & 91 & 172 & 309 & ن 1 & 0 & 7 & 32 & 65 & 186 & 个 1 & 266 & 1270 & 7310 & 17000 & 17700 & ن 1 \\
\hline Business Process Reengineering & 73 & 159 & 90 & 60 & 54 & $\Omega 0$ & 25 & 104 & 57 & 29 & 44 & $\Omega 0$ & 1130 & 6350 & 9840 & 13100 & 14100 & 个 1 \\
\hline Supply Chain Management & 22 & 243 & 1028 & 2337 & 3592 & 全 1 & 4 & 78 & 446 & 876 & 1458 & 个 1 & 1480 & 9340 & 26400 & 57900 & 57500 & $\Omega 0$ \\
\hline Customer Relationship Management & 0 & 19 & 224 & 381 & 520 & ب 1 & 0 & 7 & 104 & 137 & 223 & 个 1 & 468 & 2840 & 16400 & 20100 & 26200 & 个 1 \\
\hline Business Intelligence & 6 & 26 & 104 & 184 & 462 & 1 & 2 & 5 & 52 & 68 & 338 & 全 1 & 614 & 2150 & 12700 & 16600 & 23400 & 个 1 \\
\hline Data Warehouse Or Data Warehousing & 7 & 247 & 503 & 524 & 682 & 1 & 32 & 481 & 1565 & 2176 & 3963 & 它 1 & 47 & 2460 & 5920 & 9250 & 10400 & 仓 1 \\
\hline Data Mining & 27 & 944 & 3924 & 5751 & 8962 & 1 & 10 & 190 & 962 & 1889 & 3772 & 个 1 & 4010 & 19300 & 169000 & 463000 & 238000 & $\sqrt{2} 0$ \\
\hline Text Mining & 0 & 33 & 330 & 777 & 1687 & 1 & 0 & 2 & 66 & 233 & 644 & 全 1 & 63 & 827 & 8670 & 19300 & 20900 & 全 1 \\
\hline Web Mining & 0 & 14 & 155 & 173 & 185 & 1 & 0 & 1 & 29 & 64 & 82 & 수 1 & 16 & 461 & 5850 & 12300 & 16300 & 仓 1 \\
\hline Business Analytics & 0 & 0 & 3 & 13 & 99 & 1 & 0 & 0 & 1 & 5 & 50 & 个 1 & 11 & 32 & 423 & 1590 & 10400 & 个 1 \\
\hline Knowledge Management & 42 & 447 & 1783 & 2470 & 3111 & ب 1 & 28 & 149 & 541 & 648 & 1107 & 会 1 & 3820 & 16000 & 127000 & 205000 & 102000 & $\Omega 0$ \\
\hline Knowledge Discovery & 48 & 441 & 880 & 897 & 1183 & 1 & 6 & 108 & 208 & 310 & 454 & 수 1 & 1430 & 10400 & 25800 & 50900 & 53600 & 个 1 \\
\hline Big Data & 0 & 0 & 0 & 26 & 3946 & 1 & 0 & 0 & 0 & 4 & 1689 & 仓 1 & 0 & 0 & 721 & 2060 & 32200 & ث 1 \\
\hline
\end{tabular}

Table 1. The frequency of appearance of selected topics from 1991-2016 


\begin{tabular}{|c|c|c|c|c|c|c|c|c|c|c|c|c|}
\hline \multirow[b]{2}{*}{ Combination of topics } & \multicolumn{6}{|c|}{$\begin{array}{l}\text { Science Direct-Search by } \\
\text { Title,abstract,keywords }\end{array}$} & \multicolumn{6}{|c|}{$\begin{array}{l}\text { Google Scholar- Search all excluded } \\
\text { citations and patents }\end{array}$} \\
\hline & $\frac{n}{\frac{n}{2}}$ & 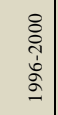 & 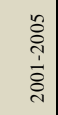 & 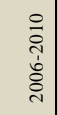 & 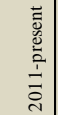 & 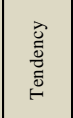 & $\begin{array}{l}\stackrel{n}{\partial} \\
\frac{\partial}{2} \\
\stackrel{2}{\circ}\end{array}$ & 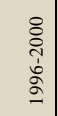 & 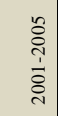 & 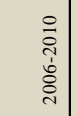 & 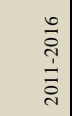 & 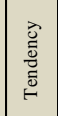 \\
\hline "ERP" and "Decision support" & 0 & 4 & 37 & 67 & 89 & 全 & 124 & 999 & 5690 & 10400 & 15300 & 个 1 \\
\hline "ERP" and "Business performance management" & - & - & - & - & - & - & 2 & 9 & 171 & 639 & 806 & 个 1 \\
\hline "ERP" and "Business process management" & 0 & 0 & 0 & 0 & 2 & 令 & 24 & 189 & 2330 & 6750 & 10200 & 个 1 \\
\hline "ERP" and "Business process reengineering" & 0 & 0 & 8 & 9 & 52 & 令 & 14 & 544 & 2710 & 3870 & 4170 & 수 1 \\
\hline "ERP" and "Supply chain management" & 0 & 3 & 45 & 49 & 63 & 包 & 95 & 1450 & 9780 & 15200 & 16800 & 1 \\
\hline 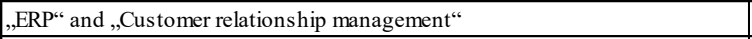 & 0 & 4 & 66 & 71 & 106 & 令 & 33 & 590 & 6130 & 10000 & 13200 & ن 1 \\
\hline "ERP" and "Business intelligence" & 0 & 1 & 33 & 39 & 68 & 全 & 22 & 310 & 3220 & 6400 & 11300 & ir 1 \\
\hline $\begin{array}{l}\text { "ERP" and "Business intelligence" and "Decision support" and "Supply } \\
\text { chain management" and "Customer relationship management" }\end{array}$ & 0 & 0 & 16 & 21 & 52 & 순 & 1 & 18 & 328 & 585 & 965 & 个 1 \\
\hline $\begin{array}{l}\text { "ERP" and "Business performance management" and "Business intelligence" } \\
\text { and "Decision support" and "Supply chain management" and "Customer } \\
\text { relationship management" }\end{array}$ & 0 & 0 & 0 & & 1 & 全 & 0 & 0 & 10 & 65 & 86 & \\
\hline $\begin{array}{l}\text { "ERP" and "business process reengineering" and "business intelligence" and } \\
\text { "decision support" and "supply chain management" and "customer } \\
\text { relationship management" }\end{array}$ & - & - & - & - & - & - & 0 & 7 & 70 & 110 & 140 & \\
\hline „ERP“ and „big data“ & - & - & - & - & - & - & 0 & 70 & 129 & 226 & 5180 & \\
\hline "ERP" + "embedded analytics" & 0 & 0 & 0 & & 13 & & 0 & 0 & 6 & 34 & 50 & 个 1 \\
\hline
\end{tabular}

Table 2. The frequency of simultaneous appearances of combination of topics from 1991-2016

The following text includes Table 3 obtained by meta analysis of research (for details see research in Halper, 2015) [17], sorted by categories from the top down: the first category represents concepts that are anticipated to decline in use over the next three years, and the remaining two categories indicate concepts that will be moderately more and much more used in the next designated period. This view of emerging trends and technologies is clearly essential for reflection and selection of a combination of business software suite, BI modules and types of analytics, platforms and ways of implementation in order to exploit the potential of each and the total potential of all of them in a given company.

\begin{tabular}{|l|c|c|}
\hline $\begin{array}{l}\text { Data Types Used for Operationalizing } \\
\text { Analytics }\end{array}$ & $\begin{array}{l}\text { Statistics of } \\
\text { today's use }\end{array}$ & $\begin{array}{l}\text { Will use for 3 years } \\
\text { from now }\end{array}$ \\
\hline Structured data(tales,records) & $90 \%$ & $8 \%$ \\
\hline App logs & $24 \%$ & $36 \%$ \\
Real time messages & $30 \%$ & $46 \%$ \\
Web logs and clickstreams & $21 \%$ & $40 \%$ \\
Machine generated data & $20 \%$ & $39 \%$ \\
\hline Data from graph databases & $15 \%$ & $32 \%$ \\
Social media data & $22 \%$ & $47 \%$ \\
Streaming, real time continous data & $16 \%$ & $46 \%$ \\
Unstructered data(audio video, text) & $15 \%$ & $48 \%$ \\
\hline & \multicolumn{2}{|c|}{} \\
\hline & Statistics of & Will use for 3 years \\
\hline Analytics Used for Operationalizing and & today's use & $9 \%$ \\
Embedding & $89 \%$ & $26 \%$ \\
\hline Reporting & $69 \%$ & $51 \%$ \\
visualisation & $28 \%$ & $59 \%$ \\
\hline Optimisation & $28 \%$ & $37 \%$ \\
Predictive analytics & $17 \%$ & $57 \%$ \\
Geospatial analytics & $22 \%$ & $46 \%$ \\
\hline What-if simulations & $17 \%$ & $51 \%$ \\
Social media analytics & $18 \%$ & $45 \%$ \\
Prescriptive analytics & $15 \%$ & \\
Text analytics & \multicolumn{2}{|c|}{} \\
\hline
\end{tabular}




\begin{tabular}{|l|c|c|}
\hline $\begin{array}{l}\text { Platforms Used for Operationalized } \\
\text { Analytics }\end{array}$ & $\begin{array}{c}\text { Statistics of } \\
\text { today's use }\end{array}$ & $\begin{array}{c}\text { Will use within3 } \\
\text { years }\end{array}$ \\
\hline Data warehouse & $74 \%$ & $19 \%$ \\
Other databases or data marts & $73 \%$ & $14 \%$ \\
BI and analytics platforms & $73 \%$ & $24 \%$ \\
Transaction systems & $59 \%$ & $16 \%$ \\
Operational data stores & $53 \%$ & $23 \%$ \\
\hline In-memory analytics platforms & $31 \%$ & $38 \%$ \\
Open source platforms & $22 \%$ & $25 \%$ \\
Data appliances & $19 \%$ & $32 \%$ \\
\hline Public cloud platforms & $19 \%$ & $39 \%$ \\
Native mobile platforms & $15 \%$ & $29 \%$ \\
Hadoop & $15 \%$ & $39 \%$ \\
In-memory grids & $13 \%$ & $27 \%$ \\
Event stream processing engines/ & $12 \%$ & $29 \%$ \\
\hline
\end{tabular}

Table 3. Data Types, Platforms and Analytics Used for Operationalizing Analytics

\section{Conclusion}

This paper presents an overview of the field with the aim of systematically linking important areas, approaches and philosophies whose understanding is necessary for successful implementation of ERP and/or SCM and/or CRM system and the establishment of effective systems for decision making support. During operation described are some issues related to the non-exploitation of potentials and non-integration of large systems, sub-optimal use of analytical tools, lack of new technological solutions, lack of understanding the phenomena big data and the like. The paper therefore proposes a set of guidelines and tips that to bypassed or eliminate these problems.

Chapter which systematically presents the concept of the affected area from selected literature has been upgraded in content around the central concept of the ERP systems. Gradually upgrading with other terms and concepts is done through their description and interpretation of the function and connecting them in relation to the ERP system. Each concept has been given a position, purpose and relationship with other areas in a continuous system of managing business performance. In doing so some guidance in terms of using new technology storage, retrieval and analysis of data has been given.

Also presented was the frequency of appearance which may also be used to monitor the development and character of processed concepts, and thus demonstrating the need to also consider their mutual relations and not just the concepts individually. Meta analysis has produced graphs that describe the anticipated development of certain technologies, types of data, analytical tools, and highlights those that are anticipated to decline in popularity and the ones that will be more and more used in the next few years. This concise view of future trends is also important in the assessment criteria for the selection of software, tools and types of implementation. This paper is intended to gain insight on the complexity of the field of business management and exploitation of the full potential of software packages that are offered today in the market in order to find the best combination for a given company. The further course of research would go into setting up a comprehensive framework which sets the basic structure and configuration of the business suites and after that to create a support system in the selection of such a configuration.

\section{Acknowledgments}

The research has been conducted under the project "Extending the information system development methodology with artificial intelligence methods" (reference number 13.13.1.2.01.) supported by the University of Rijeka (Croatia).

\section{References}

[1] Avram,C.D., ERP inside Large Organizations, Informatica Economică, vol. 14, no. 4,2010

[2] Gligora Marković, M.; Pogarčić, I.; Šuman, S.,Managements' role in development of Information system // Annals of DAAAM for 2012. \& Proceedings of the 23rd International DAAAM Symposium / Katalinić, Branko (ur.).Vienna : DAAAM International, 2012. 737-742

[3] Eckerson,W.,W.,, Performance Dashboards, John Wiley \& Sons, Inc. 2011

[4] Butler, B., Cloud Cronicles, 2015., http://www.networkworld.com/article/2973963/big-data-business-intelligence/5problems-with-big-data.html , Accessed on: 05.01.2016

[5] Aziza, B., Big Data 'A-Ha' Moment? Forbes CIO Central , February 25, 2013 at URL http://www.forbes.com/sites/ciocentral/2013/02/25/big-data-a-ha-moment/, Accessed on: 12.5.2015

[6] Ehrenberg, R. (2012, January 19). What's the big deal about Big Data? InformationArbitrage.com blog post. At URL http://informationarbitrage.com/post/16121669634/whats-the-big-dealabout-big-data (12.5.2015) 
[7] Morris, J. ( 2012, July 16), Top 10 categories for Big Data sources and mining technologies. ZDNet. At URL http://www.zdnet.com/article/top-10-categories-for-big-data-sources-and-mining-technologies/ (12.5.2015.)

[8] Mayer-Schönberger, V., \& Cukier, K. (2013). Big data: A revolution that will transform how we live, work, and think . New York: Houghton Mifflin Harcourt, 2013

[9] Heudecker, N, "Hype Cycle for Big Data, 2013," July 31., 2013, (https://www.gartner.com/doc/2574616).

[10] Devlin, B. (2013a, February 5). B-eye-Network blog . At URL http://www.b-eyenetwork.com/blogs/devlin/archives/2013/02/, Accessed on: 12.5.2015

[11] Devlin, B. (2013b, March 4). Big data-Please, drive a stake through its heart!. B-eye-Network blog. At URL http://www.b-eye-network.com/blogs/devlin/archives/2013/03/, Accessed on: 12.5.2015

[12] Power, D. J.,Creating a Data-Driven Global Society, Springer International Publishing Switzerland 201513 L.S. Iyer, D.J. Power (eds.), Reshaping Society through Analytics, Collaboration, and Decision Support, Annals of Information Systems, Volume 18,2015,pp 13-28

[13] Dyche 2013, Dyche, J. (2013, March 13). Big data's three-legged stool. Information Management . At URL http://www.information-management.com/news/big-data-three-legged-stool-10024077-1.html , Accessed on: 12.5.2015., registration needed

[14] Šuman, S., Gligora Marković, M., Jadro, B., Decision's support and the business intelligence - what needs to be learnt?, Zbornik Veleučilišta u Rijeci, Vol. 2, (2014.), in press, No. 1

[15] Benders, J., Batenburg,R., Van der Blonk, H., Sticking to standards; technical and other isomorphic pressures in deploying ERP systems, Information \& Management 43,2006, 194-203

[16] Liao, X., Li, Y., Lu, B. , A model for selecting an ERP system based on linguistic information processing. Information Systems, 32, 2007, 1005-1017

[17] Halper, F., Operationalizing and Embedding Analytics for Action, Best practices report 2015 by TDWI

[18] Hallikainen,P., Kimpimaki, H., Kivijarvi, H., Supporting the module sequencing decision in the ERP implementation process. In Proceedings of the 39th Hawaii international conference on system sciences, 2006.

[19] Frano, J., "ERP System Acquisition Project Planning," in ERP vol. 2010, I. Toolkit, Ed., ed: IT Toolkit, 2008

[20] Eckartz, S., et al., A Conceptual Framework for ERP Benefit Classification: A Literature Review , Technical Report, 2009

[21] Lai ,V.S. et al., What influences ERP beliefs — Logical evaluation or imitation? / Decision Support Systems 50 (2010) 203-212

[22] Davenport, T. H., "Putting the Enterprise into the Enterprise System," Harvard Business Review, 1998,Vol. 76, pp. 121-131

[23] Palaniswamy, R., Frank, T., Enhancing manufacturing performance with ERP systems, Information Systems Management (2000 Summer) 43-55

[24] Holsapple ,C.W., Sena, M.P. ,ERP plans and decision-support benefits Decision Support Systems 38 , 2005 , $575-590$

[25] Tsai M.T. et al., Beyond ERP implementation: The moderating effect of knowledge management on business performance, Total Quality Management Vol. 22, No. 2, February, 2011, 131-144

[26] Li, C., ERP packages: what's next? Information Systems Management (Summer ,1999) 31-35

[27] Riives, J.; Karjust, K.; Küttner, R.; Lemmik, R.; Koov, K.; Lavin, J., Software development platform for integrated manufacturing engineering system , 8th International DAAAM Baltic Conference "INDUSTRIAL ENGINEERING" 19-21 April 2012, Tallinn, Estonia

[28] Shafiei, F. et al. , Multi-enterprise collaborative decision support systemExpert Systems with Applications 39 (2012) 7637-7651

[29] Lemmik, R.; Otto, T.; Küttner, R., Knowledge Management Systems For Service Desk Environment , 9th International DAAAM Baltic Conference "INDUSTRIAL ENGINEERING" 24-26 April 2014, Tallinn, Estonia

[30] Bolloju, N., Khalifa, M.,Turban, E., Integrating knowledge management into enterprise environments for the next generation decision support, Decision Support Systems, Vol. 33, pp.163-176, 2002

[31] Krogh, G., Nonaka, I. and Aben, M.,"Making the most of your company's knowledge: A strategic framework," Long Range Planning, 2001, Vol. 34, No. 4, pp. 421-439

[32] Ifinedo, P. , "Extending the Gable et al. enterprise systems success measurement model: A premilinary study," Journal of Information Technology Management, Vol. 17, No. 1, pp.14-33.,2006

[33] Jeng ,D.J.F. , Dunk, N., Knowledge Management Enablers and Knowledge Creation in ERP System Success, International Journal of Electronic Business Management, 54 Vol. 11, No. 1,2013

[34] Zhang ,H., Liang, Y., A Knowledge Warehouse System for Enterprise Resource Planning Systems, Systems Research and Behavioral Science Syst. Res.23,169-176 (2006)

[35] Nemati H, et al.,. Knowledge warehouse: an architectural integration of knowledge management, decision support, artificial intelligence and data warehousing. Decision Support Systems 33(2) ,2002: 143-161

[36] Robb ,D., Analytics Playing Greater Role in ERP, at URL http://www.enterpriseappstoday.com/erp/analyticsplaying-greater-role-in-erp.html , Accessed on: 12.5.2015

[37] Monk ,E., F., Wagner B., J., Concepts in Enterprise Resource Planning, Fourth Edition, 2013 Course Technology, Cengage Learning

[38] Su, Y.F., Yang, C., Why are enterprise resource planning systems indispensable to supply chain management?/ European Journal of Operational Research 203 (2010) 81-94

[39] Kurbel ,K., E. Enterprise Resource Planning and Supply Chain Management Functions, Business Processes and Software for Manufacturing Companies, Springer-Verlag Berlin Heidelberg 2013

[40] Turban, E., Sharda, R., Delen, D., Decision Support and Business Intelligence Systems, Pearson , 2010

[41] Elragal,A., ERP and Big Data: The Inept CoupleProcedia Technology 16 ( 2014 ) 242 - 249) 